\title{
Strategi Peningkatan Kualitas Lulusan Mahasiswa Program Studi Teknik Industri Universitas XYZ Yogyakarta
}

\author{
Emmy Nurhayati ${ }^{1}$, Elly wuryaningtyas Yunitasari $^{1}$ \\ ${ }^{1}$ Program Studi Teknik Industri \\ Universitas Sarjanawiyata Tamansiswa Yogyakarta \\ Jl. Miliran 16, Yogyakarta 55165 \\ email : emmy.nurhayati@ustjogja.ac.id \\ doi: https://doi.org/10.31315/opsi.v13i1.3475
}

Received: $15^{\text {th }}$ June 2019; Revised: $2^{\text {nd }}$ July 2020; Accepted: $2^{\text {nd }}$ July 2020;

Available online: $2^{\text {nd }}$ July 2020; Published regularly: June 2020

\begin{abstract}
The higher level of work competition that requires an academic degree makes an educational institution must improve the quality of graduates. Graduates of Industrial Engineering Study Program as an output of service industry, must have the quality and qualifications required by the users of graduates. Therefore, the college must prepare its students to compete with the ability and competence that can be relied on to obtain a decent job or create small industry. The results of the development of this strategy are expected to realize the students of Industrial Engineering Study Program Universitas XYZ Yogyakarta which has the advantages of: graduating with a short lecture period, high GPA and competent in the field of industrial engineering, has the ability to speak especially foreign languages and reliable IT understanding. The advantages are uses SWOT, EFAS and IFAS approaches. The right strategy recommendation to improve the quality of students is an entrance exam for new students. Equips students of Industrial engineering study Program with professional certification owned, partnering with SME for the creation of new entrepreneurial opportunities, equip students with industrial engineering's software, establishing cooperation with the companies for study excursion, practice and data retrieval or final task internship and also involving the students in local, national and international competitions.
\end{abstract}

Keywords: Industrial Engineering; SWOT; EFAS; IFAS

\begin{abstract}
ABSTRAK
Tingginya tingkat persaingan dunia kerja yang membutuhkan gelar akademik menjadikan institusi pendidikan harus meningkatkan kualitas lulusannya. Lulusan Program Studi Teknik Industri sebagai luaran dari industri jasa, harus memiliki kualitas dan kualifikasi yang dibutuhkan oleh para pengguna lulusan. Oleh karena itu pihak perguruan tinggi harus menyiapkan mahasiswanya untuk dapat bersaing dengan mempunyai kemampuan dan kompetensi yang dapat diandalkan agar bisa mendapatkan pekerjaan yang layak atau menciptakan lapangan kerja. Hasil pengembangan strategi ini diharapkan dapat mewujudkan mahasiswa Program Studi Teknik Industri Universitas XYZ Yogyakarta yang mempunyai keunggulan yaitu: lulus dengan masa kuliah singkat, IPK tinggi dan berkompeten di bidang Teknik Industri, mempunyai kemampuan berbahasa khususnya bahasa asing dan pemahaman IT yang bisa diandalkan. Keunggulan tersebut perlu dilakukan dengan suatu strategi yaitu menggunakan pendekatan Strengths, Weaknesses, Opportunies, Treaths, External Strategic Factors Analysis Summary, kemudian dilanjutkan dengan Internal Strategic Factors Analysis Summary. Rekomendasi strategi yang tepat untuk meningkatkan kualitas lulusan adalah ujian masuk bagi mahasiswa baru diperketat seleksinya, membekali lulusan dengan sertifikasi profesi yang dimiliki, menjalin kemitraan dengan UMK untuk peluang terciptanya wirausaha baru, membekali mahasiswa dengan software Teknik Industri, menjalin kerjasama dengan perusahaan untuk study excursion, kerja praktik dan pengambilan data atau magang tugas akhir serta mengikutsertakan mahasiswa dalam lomba-lomba tingkat lokal, nasional dan internasional.
\end{abstract}

Kata Kunci: Teknik Industri; SWOT; EFAS; IFAS

\section{PENDAHULUAN}

Proses kegiatan akademik atau perkuliahan di suatu perguruan tinggi, haruslah mampu memberikan kemampuan akademik hard skill bagi para mahasiswanya dan juga menuntut memiliki kemampuan personal (soft skills) dan sikap (attitude) yang baik. Hal ini dimaksudkan agar mahasiswa siap memasuki dunia kerja yang tentu saja dibutuhkan unsur-unsur tersebut.

Pengetahuan, keterampilan/keahlian dan sikap yang dimiliki perlu ditunjukkan dengan 
adanya hasil atau bukti nyata. Kurikulum berbasis kompetensi mencakup beberapa kompetensi yang wajib dan harus dimiliki oleh mahasiswa Program Studi Teknik Industri antara lain: (1) kompetensi kognitif, berupa pengetahuan dan pemahaman khusus; (2) kompetensi afektif, berupa hal-hal yang berkenaan dengan nilai-nilai, sikap, apresiasi dan interes; (3) kompetensi kinerja sampai pada kemampuan mendemonstrasikan perilaku atau keterampilan; (4) kompetensi hasil berupa kemampuan untuk menghasilkan perubahan dalam bentuk lain; dan (5) kemampuan berapresiasi (Unimed, 2004:4).

Selama ini mahasiswa Program Studi Teknik Industri Universitas XYZ Yogyakarta lulus dengan masa studi yang lama (lebih dari 8 semester), Indeks Prestasi Kumulatif (IPK) yang standar (berkisar 3,00-3,10), kemampuan berbahasa asing yang kurang dengan nilai TOEFL di bawah 400 dan pemahaman IT atau software-software Teknik Industri yang kurang. Hal ini membuat masa tunggu untuk mendapatkan pekerjaan menjadi lama, apalagi kemampuan untuk menciptakan lapangan kerja juga kurang.

Analisis data yang dilakukan dengan metode SWOT, IE, EFI dan juga EFE pada Lulusan Teknik Industri di suatu PTS X menunjukkan bahwa perancangan strategi untuk pengembangan daya saing pada lulusan yang dihasilkan berada pada sel lima (V). Diperoleh hasil bahwa ada 78 poin yang dapat dilakukan berdasarkan analisis SWOT dari strategi SO, WO, ST, WT (Nurdin, 2017).

Agar dapat diwujudkan mahasiswa yang mempunyai keunggulan yaitu: lulus dengan masa kuliah singkat, IPK tinggi serta mempunyai kemampuan berbahasa dan pemahaman IT yang bisa diandalkan maka diperlukan strategi dengan menggunakan pendekatan External Strategic Factors Analysis Summary atau EFAS, Internal Strategic Factors Analysis Summary atau IFAS dan Strengths, Weaknesses, Opportunies, Treaths (SWOT), (Rangkuti, 2011).

\section{METODE}

Langkah yang dilakukan dalam perancangan strategis bagi peningkatan kualitas lulusan ini yaitu: 1. Melakukan perancangan belief dan value; 2. Melakukan perancangan strategi dan tujuan bersaing; 3. Melakukan identifikasi business process; 4. Melakukan perancangan struktur organisasi (Porter, 2007).
Sedangkan langkah yang dilakukan dalam menentukan faktor pada strategi eksternal: 1) Melakukan penyusun pada kolom 1 yang berisi peluang dan ancaman; 2) Memberikan besaran bobot pada masing-masing faktor di kolom 2, dari sangat penting sampai tidak penting. Jumlah total bobot dari keseluruhan faktor peluang maupun ancaman $=1$; 3) Pada kolom 3 dilakukan penghitungan rating dengan memberikan skala mulai dari 4 (outstanding) sampai dengan 1 (poor); 4) Bobot pada kolom 2 dan rating pada kolom 3 dilakukan pengalian untuk mengisi kolom 4 yang berupa faktor pembobotan; 5) Pada kolom 5 digunakan untuk memberikan alasan terhadap faktor-faktor tertentu yang dipilih; 6) Pada kolom 4 dilakukan penjumlahan skor pembobotan yang bertujuan untuk mendapatkan total skor pembobotan (Porter, 1993).

Kemudian melakukan evaluasi terhadap faktor internal yang bertujuan untuk mengetahui kekuatan dan kelemahan yang dimiliki. Langkah yang dilakukan dalam menentuan faktor pada strategi internal ini yaitu: 1) Kolom 1 yaitu menentukan faktor yang menjadi strength maupun weakness; 2) Kemudian memberi bobot pada masing-masing faktor dimulai dengan yang paling penting sampai dengan tidak penting. Jumlah total bobot dari keseluruhan faktor kekuatan maupun kelemahan $=1$; 3) Pada kolom 3 dilakukan penghitungan rating dengan memberikan skala mulai dari 4 (outstanding) sampai dengan 1 (poor); 4) Bobot pada kolom 2 dan rating pada kolom 3 dilakukan pengalian untuk mengisi kolom 4 yang berupa faktor pembobotan; 5) Pada kolom 5 digunakan untuk memberikan alasan terhadap faktor-faktor tertentu yang dipilih; 6) Pada kolom 4 dilakukan penjumlahan skor pembobotan yang bertujuan untuk mendapatkan total skor pembobotan (Porter, 1993).

Pada dasarnya, langkah untuk evaluasi terhadap faktor internal dan eskternal adalah sama, tetapi bagaimana faktor-faktor itu mewakili kondisi di dalam dan di luar institusi maupun kelemahan dan kekuatan yang dimilikinya.

\section{HASIL DAN PEMBAHASAN}

Mahasiswa Program Studi Teknik Industri Universitas XYZ Yogyakarta disiapkan untuk dapat bersaing dengan mempunyai kemampuan yang dapat diandalkan agar bisa mendapatkan pekerjaan yang layak atau menciptakan lapangan kerja yang berguna untuk masyarakat. 
Mahasiswa diharapkan dapat lulus dengan masa kuliah singkat, IPK tinggi serta mempunyai kemampuan berbahasa dan pemahaman IT yang bisa diandalkan sehingga para lulusan yang dihasilkan akan dapat bersaing dengan para lulusan dari perguruan tinggi yang lain (Sitanggang, 2019).

Proses serta Masukan Perancangan Tujuan dan Strategi:

a. Project Management Institute: Rahmat Mulyana Praktisi dan Akademisi, Suci Miranda Branch Director PMI Jogja dan Akademisi

b. Studi Banding ke UII, menerapkan Kurikulum BKSTI dan Mercy of God (99 Prinsip) dan Penguatan Kerohanian c. Workshop Kurikulum BKSTI Menghadapi Industri 4.0

d. Keikutsertaan dalam IPTEK Bagi Kewirausahaan (IBK)

e. Produksi Rutin Wedang Uwuh, Terciptanya Formula dan Kemasan Baru, Standarisasi Proses Produksi yang dimulai dari Input sampai kepada Output yang dihasilkan.

f. Refreshing serta Uji Kompetensi LSP

g. Ketikutsertaan dalam Lomba: Descomfirst: Alat Bantu Pembentuk Bakpia; PMC: Waste Water Treatment; I-Create: Alat Bantu Berkendara bagi Penyandang Tuna Rungu dan Cerebral Palsy Hand Automatic V2.

Tabel 1. Keselarasan Profil Lulusan Prodi Teknik Industri dengan Ajaran Tamansiswa (Feasible)

\section{AJARAN TAMANSISWA}

Tri-N: Niteni, Niroke, Nambahi

Tri Sakti Jiwa: Cipta, Rasa, Karsa

\section{Prinsip Kemandirian (Opor Bebek Mateng Saka Awake Dhewek), Prinsip Ekonomi Kerakyatan}

Tri Juang: berjuang memberantas kebodohan, kemiskinan, ketertinggalan

Ngandel-Kendel-Bandel-Kandel: percaya diri, berani, tahan banting, tidak mudah putus asa

Tri Sakti Jiwa: Cipta, Rasa, Karsa

Tri-N: Niteni, Niroke, Nambahi

Tut Wuri Handayani

Triko: Kooperatif, Konsultatif, dan Korektif

Tri Logi Kepemimpinan: Ing Ngarsa Sung Tuladha, Ing Madya Mangun Karsa, Tut Wuri Handayani Tri Pantangan: (pantangan menyalahgunakan kekuasaan, keuangan, kesusilaan)

Tri Hayu: Memayu Hayuning Salira, Memayu Hayuning Bangsa, Memayu Hayuning Manungsa Democratic en Leiderschap: Demokrasi dan Pimpinan Kebijaksanaan

\section{Tri-Nga: Ngerti, Ngrasa, Nglakoni}

Ning-Neng-Nung-Nang: (dengan pikiran hening, tenang, diam tidak mudah emosi, keteguhan, kekuatan hati akhirnya memperoleh kemenangan)

(Tauchid, 2011)

\section{FEASIBLE}

F: Futuristic Thinker, terarah, tertuju ke masa depan, modern sekali

E: Entrepreneurship, melakukan usaha sebagai wiraswasta yang memiliki bakat dalam mengenali produk baru untuk dapat menentukan cara produksi baru dan memasarkannya

A: Active, Aktif, giat, gesit, kuat, bersemangat, ramai, keras, yg bekerja, masih bekerja, energik, yg hidup, dinamis, bertenaga

S: Skillful, Mahir, pandai, trampil, cekatan, cakap, ulung, akas, gesit

I: Innovative, inovatif, bersifat memperkenalkan sesuatu yang baru atau kreasi baru yang bersifat pembaruan

B: Better, lebih baik, memperbaiki, melebihi, mempertajam

L: Leadership, Kepemimpinan, perihal pemimpin, cara memimpin

E: Empathy, Empati, mempunyai empati, tenggang rasa, tepo seliro, mempunyai rasa yang sama untuk mengidentifikasi dirinya seperti perasaan atau pikiran orang atau kelompok lain, (Prodi Teknik Industri UST, 2018) 
Tabel 2. External Strategic Factors Analysis Summary (EFAS)

\section{FAKTOR-FAKTOR STRATEGI EKSTERNAL}

BOBOT RATING
KOMENTAR

Peluang

- Meningkatnya jumlah lulusan SMA yang lanjut ke Perguruan Tinggi.

- Adanya peluang pendanaan untuk kegiatan Penelitian dan Pengabdian kepada Masyarakat dari DIKTI, instansi pemerintah dan swasta untuk dosen juga mahasiswa.

- Jenis usaha di Indonesia didominasi oleh usaha yang berskala Usaha Mikro dan Kecil (UMK) sebanyak 98,33\%.

- Peranan Usaha mikro dan kecil (UMK) dalam ekonomi Indonesia, pada jumlah usaha maupun dari pencyerapan lapangan kerja.

- Berbagai permasalahan yang dialami Usaha mikro dan kecil nasional

- Banyaknya Usaha Mikro dan Kecil yang berada di sekitar DIY, di Pulau Jawa maupun luar Pulau Jawa.

- Usaha Mikro dan Kecil yang ada di Indonesia terbuka untuk melakukan kerja sama.

(Wilantara, 2016)

$\begin{array}{llll}0.2 & 3 & 0.6 & \text { Strategi promosi } \\ 0.1 & 2 & 0.2 & \text { Kerjasama } \\ 0.1 & 2 & 0.2 & \text { Wirausaha baru } \\ 0.08 & 1 & 0.08 & \begin{array}{l}\text { Pengabdian } \\ \text { masyarakat }\end{array} \\ 0.1 & 2 & 0.2 & \begin{array}{l}\text { Kerjasama } \\ 0.1\end{array} \\ & 2 & 0.2 & \begin{array}{l}\text { Penelitian dan } \\ \text { Pengabdian } \\ \text { Masyarakat }\end{array} \\ 0.2 & 3 & 0.6 & \text { MOU }\end{array}$

\section{Ancaman}

- Indonesia termasuk daerah rawan bencana dan

0.02

2

0.04

Perlu hati-hati

- Banyaknya Usaha Mikro dan Kecil (UMK)

0.05

yang berada di daerah terpencil dan sulit dijangkau

- Belum stabilnya perekonomian Indonesia dan ekonomi global yang berdampak pada pertumbuhan Usaha Mikro dan Kecil

- Kebijakan terkait Masyarakat Ekonomi Asean (MEA)

\begin{tabular}{c} 
Total \\
\hline Matriks EFE digunakan untuk \\
menganalisis dan mengevaluasi berbagai faktor
\end{tabular}
eksternal yang ada, berupa kekuatan dan kelemahan yang sekiranya dianggap penting untuk dilakukan pembobotan dan rating (Riyanto, 2017).

Rekomendasi strategi yang tepat dalam upaya untuk meningkatkan kualitas lulusan mahasiswa Program Studi Teknik Industri Universitas XYZ Yogyakarta adalah sebagai berikut:

a. Ujian masuk bagi mahasiswa baru Program Studi Teknik Industri diperketat seleksinya.

$0.02 \quad 2 \quad 0.04 \quad$ Diperhatikan

$\begin{array}{llll}0.03 & 1 & 0.03 & \text { Tantangan baru }\end{array}$
1.00 2.29

b. Membekali lulusan mahasiswa Program Studi Teknik Industri dengan sertifikasi profesi yang dimiliki.

c. Menjalin kemitraan dengan UMK-UMK untuk peluang terciptanya wirausaha baru.

d. Membekali mahasiswa Program Studi Teknik Industri dengan software-software Teknik Industri.

e. Menjalin kerjasama di perusahaanperusahaan tempat mahasiswa Program Studi Teknik Industri melakukan excursion study, kerja praktek dan pengambilan data atau magang tugas akhir. 
Tabel 3. Internal Strategic Factors Analysis Summary (IFAS)

FAKTOR-FAKTOR STRATEGI INTERNAL BOBOT RATING X

KOMENTAR

RATING

Kekuatan

- Visi dan Misi Program Studi Teknik Industri sejalan dengan Visi Misi Universitas

Sarjanawiyata Tamansiswa (UST) dan Fakultas Teknik.

- Visi dan Misi Program Studi Teknik Industri turut serta mendukung program pemerintah yang dituangkan dalam Nawa Cita Pemerintah Indonesia.

- Adanya kekhasan visi Program Studi Teknik Industri yang memfokuskan pada pengembangan Industri Kecil dan Menengah.

- Pembelajaran berasaskan Ajaran Luhur Tamansiswa, diantaranya adalah tentang kemandirian dan kepemimpinan.

- Program Studi Teknik Industri memiliki Skema Sertifikasi Profesi yaitu Konsultan Desain Kemasan untuk Industri Kecil dan Menengah dan Penerapan Sistem Manajemen Keselamatan dan Kesehatan Kerja (SMK3).

- Memiliki kepedulian terhadap para penyandang disabilitas (difabel)

- Kualifikasi dan keahlian Sumber Daya Manusia (SDM), baik Dosen maupun tenaga kependidikan memadai dan mempunyai komitmen yang tinggi dalam mencapai visi.

- Adanya dukungan penuh dari Universitas untuk mencapai visi dan misi.

- Letak Strategis (berada di pusat Kota Yogyakarta)

- Memiliki sarana dan prasarana yang memadai (Lab terpadu, gedung baru Fakultas Teknik serta jaringan mitra baik nasional maupun internasional).

Kelemahan

- Mayoritas Dosen bukan lulusan dari Universitas Sarjanawiyata Tamansiswa

- Banyaknya Dosen Program Studi Teknik Industri yang menduduki jabatan struktural

f. Mengikutsertakan mahasiswa Program Studi Teknik Industri dalam lomba-lomba tingkat lokal, nasional dan internasional.

\section{KESIMPULAN}

Perancangan strategi untuk meningkatkan kualitas lulusan mahasiswa Program Studi

\begin{tabular}{llll}
0.05 & 4 & 0.2 & Strategi \\
0,05 & 3 & 0.15 & $\begin{array}{l}\text { Menyusun } \\
\text { strategi yang } \\
\text { lain }\end{array}$ \\
\hline 1.00 & 2.59 & \\
\hline
\end{tabular}

\begin{tabular}{|c|c|c|c|}
\hline 0.08 & 1 & 0.08 & Potensi baik \\
\hline 0.07 & 1 & 0.07 & Positif \\
\hline 0.09 & 3 & 0.27 & Dampak positif \\
\hline 0.06 & 1 & 0.06 & Modal dasar \\
\hline 0.2 & 4 & 0.8 & Potensial \\
\hline 0.07 & 3 & 0.21 & Kekhasan \\
\hline 0.08 & 2 & 0.16 & Modal dasar \\
\hline 0.08 & 2 & 0.16 & Potensi baik \\
\hline 0.09 & 3 & 0.27 & Potensial \\
\hline 0.08 & 2 & 0.16 & Modal dasar \\
\hline
\end{tabular}

Teknik Industri Universitas XYZ Yogyakarta dimulai dengan implementasi ajaran luhur Tamansiswa yang diselaraskan dengan Jiwa FEASIBLE (Futuristic Thinker, Entrepreneurship, Active, Skillful, Inovative, Better, Leadership, Empathy) serta pembuatan Matrik Strengths, Weaknesses, Opportunies, Treaths (SWOT) untuk mengetahui 
pengembangan dari strategi SO, WO, ST, WT dan pembuatan External Strategic Factors Analysis Summary (EFAS) dan Internal Strategic Factors Analysis Summary (IFAS).

\section{DAFTAR PUSTAKA}

Nurdin, Burhan. (2017). Strategi Pengembangan Daya Saing Lulusan Teknik Industri Fakultas Teknik: Studi Kasus PTS X di Kopertis Wilayah II. Operations Excellence, 9(2).

Porter, Michael E. (1993). Keunggulan Bersaing: Menciptakan dan Mempertahankan Kinerja Unggul. Cetakan ke 2. Jakarta: Erlangga.

Porter. (2007). Strategy Bersaing (Competitive Strategy): Teknik Menganalisis Industri dan Pesaing, Tangerang: Karisma Publishing Group.

Program Studi Teknik Industri UST. (2018). Profil Program Studi Teknik Industri. Yogyakarta: Universitas Sarjanawiyata Tamansiswa.
Rangkuti, F. (2011). Analisis SWOT Teknik Membedah Kasus Bisnis. Jakarta: PT. Gramedia Pustaka Utama.

Riyanto, Setyo. (2017). Pengambilan Keputusan Strategis Berbasis EFAS/IFAS/SFAS/AHP. Bandung: Paramedia Komunikatama.

Sitanggang, Nathanael, Putri Lynna A. Luthan \& Hamid, Abdul. (2019). Strategi Meningkatkan Kualitas Lulusan Melalui Ketepatan Manajemen. Yogyakarta: Deepublish.

Tauchid, Muchammad. (2011). Perjuangan dan Ajaran Hidup Ki Hadjar Dewantara. Cetakan Ketiga. Yogyakarta: Majelis Luhur Tamansiswa.

Unimed. (2004). Pedoman Pengembangan Standar Mutu Lulusan dan Kurikulum Berbasis Kompetensi. Medan: Universitas Negeri Medan.

Wilantara, Rio F., \& Susilawati. (2016). Strategi \& Kebijakan Pengembangan UMKM. Bandung: Refika Aditama. 